\title{
Surgery versus radiosurgery for facial nerve schwannoma: a systematic review and meta-analysis of facial nerve function, postoperative complications, and progression
}

\author{
Juliana Rotter, MD, ${ }^{1}$ Victor M. Lu, MD, PhD, ${ }^{1}$ Christopher S. Graffeo, MD, MS, ${ }^{1}$ Avital Perry, MD, ${ }^{1}$ \\ Colin L. W. Driscoll, MD, ${ }^{1,2}$ Bruce E. Pollock, MD, ${ }^{1,3}$ and Michael J. Link, MD ${ }^{1,2}$ \\ Departments of ${ }^{1}$ Neurosurgery, ${ }^{2}$ Otolaryngology-Head and Neck Surgery, and ${ }^{3}$ Radiation Oncology, Mayo Clinic, Rochester, \\ Minnesota
}

\begin{abstract}
OBJECTIVE Intracranial facial nerve schwannomas (FNS) requiring treatment are frequently recommended for surgery or stereotactic radiosurgery (SRS). The objective of this study was to compare facial nerve function outcomes between these two interventions for FNS via a systematic review and meta-analysis.
\end{abstract}

METHODS A search of the Ovid EMBASE, PubMed, SCOPUS, and Cochrane databases from inception to July 2019 was conducted following PRISMA guidelines. Articles were screened against prespecified criteria. Facial nerve outcomes were classified as improved, stabilized, or worsened by last follow-up. Incidence was pooled by random-effects meta-analysis of proportions.

RESULTS Thirty-three articles with a pooled cohort of 519 patients with FNS satisfied all criteria. Twenty-five articles described operative outcomes in 407 (78\%) patients; 10 articles reported SRS outcomes in $112(22 \%)$. In the surgical cohort, facial nerve function improved in $23 \%(95 \% \mathrm{Cl} 15 \%-32 \%)$, stabilized in $41 \%(95 \% \mathrm{Cl} 32 \%-50 \%)$, and worsened in $30 \%(95 \% \mathrm{Cl} 21 \%-40 \%)$. In the SRS cohort, facial nerve function was improved in $20 \%(95 \% \mathrm{Cl} 9 \%-34 \%)$, stable in $66 \%(95 \% \mathrm{Cl} 54 \%-78 \%)$, and worsened in 9\% (95\% $\mathrm{Cl} 3 \%-16 \%)$. Compared with SRS, microsurgery was associated with a significantly lower incidence of stable facial nerve function $(p<0.01)$ and a significantly higher incidence of worsened facial nerve function $(p<0.01)$. Tumor progression and complication rates were comparable. Outcome certainty assessments were very low to moderate for all parameters.

CONCLUSIONS Unfavorable facial nerve function outcomes are associated with surgical treatment of intracranial FNS, whereas stable facial nerve function outcomes are associated with SRS. Therefore, SRS should be recommended to patients with FNS who require treatment, and surgery should be reserved for patients with another indication, such as decompression of the brainstem. Further study is required to definitively optimize and validate management strategies for these rare skull base tumors.

https://thejns.org/doi/abs/10.3171/2020.6.JNS201548

KEYWORDS facial nerve schwannoma; seventh cranial nerve; surgery; resection; stripping; stereotactic radiosurgery; Gamma Knife; skull base

I NTRACRANIAL facial nerve schwannomas (FNS) are slow-growing, rare, benign tumors that arise from the myelin-producing Schwann cells of the facial nerve (cranial nerve [CN] VII). Although common presenting symptoms include asymmetrical hearing loss and facial weakness, patients with cerebellopontine angle FNS also frequently present with hemifacial spasm, headache, mass effect, hydrocephalus, or nonspecific symptoms..$^{1-3}$

Given their slow rate of growth and increased potential for treatment morbidity as compared with vestibular schwannomas (VSs), FNS are often observed initially, with treatment reserved for tumors demonstrating progressive growth or worsening symptoms. ${ }^{1,4}$ Although resection was the historical standard of care, over the past 3 decades stereotactic radiosurgery (SRS) has been established as a safe and effective alternative treatment, which offers excellent tumor control and very low risk of treatment-associated facial nerve morbidity. ${ }^{5-7}$ Although numerous studies have compared surgery and SRS for FNS, the contemporary standard of care for tumors with an indication for treatment remains controversial. Correspondingly, this study compared outcomes of patients with FNS who underwent

ABBREVIATIONS CN = cranial nerve; $E S=$ effect size; FNS = facial nerve schwannomas; GRADE = Grading of Recommendations, Assessment, Development and Evaluations; HB = House-Brackmann; PICOS = Population, Intervention, Comparator, Outcome, Study type; SRS = stereotactic radiosurgery; VS = vestibular schwannoma. SUBMITTED April 30, 2020. ACCEPTED June 8, 2020.

INCLUDE WHEN CITING Published online October 30, 2020; DOI: 10.3171/2020.6.JNS201548. 
the reported surgical strategies for this tumor, including surgical removal with grafting, surgical removal without grafting, and canal decompression, with those treated with Gamma Knife SRS. To the best of our knowledge, this represents the first systematic review and meta-analysis of observational studies reporting facial nerve outcomes after either surgery or SRS treatment of intracranial FNS, and we conducted it in order to better inform future treatment decision-making and patient counseling when discussing surgery and SRS as treatment options.

\section{Methods}

\section{Search Strategy}

The search strategy was designed using the PICOS format: among patients with intracranial FNS (Population) treated with surgery (Intervention) compared with SRS (Comparator), what are the postoperative facial nerve function outcomes (Outcome), based on observational studies (Study type)? The literature review was conducted according to the PRISMA guidelines and recommendations. ${ }^{8}$ Electronic searches were performed using the Ovid EMBASE, PubMed, SCOPUS, and Cochrane databases from inception to July 2019 (Appendix). The literature was searched independently by two investigators (J.R., V.M.L.) using the following string of terms: (facial schwannoma) OR (facial nerve schwannoma) OR (facial neuroma) OR (facial nerve neuroma) AND (surgery OR radiosurgery OR SRS).

\section{Selection Criteria}

The included articles reported patients with the following characteristics: 1) diagnosed with intracranial FNS and verified based on neuroanatomical location; 2) undergoing primary treatment via surgery or SRS; 3 ) with postoperative facial nerve function reported; and 4) aged $>18$ years. Studies inclusive of both sporadic and syndromic patients without parsed data were excluded. All surgical approaches, including gross-total resection or partial decompression with or without nerve graft, were considered eligible for inclusion, and SRS by Gamma Knife therapy was the only SRS modality considered. Exclusion criteria were as follows: 1) schwannomas arising from other cranial nerves; 2) lesions arising in the setting of neurofibromatosis type 2 or other genetic tumor syndromes; 3 ) extracranial lesions including parotid locations; and 4) publications reporting on $<3$ patients, to reduce the risk of selection bias. For institutions publishing serial overlapping cohorts, only the most complete reports were included for quantitative assessment at each time interval. Publications were limited to those written in the English language.

\section{Data and Extraction}

Outcomes were abstracted directly from article texts, tables, and figures independently by two investigators (J.R., V.M.L.). The primary endpoint was facial nerve function as measured by changes in House-Brackmann (HB) grade from time of treatment to last follow-up, using a 3-tier Likert scale (e.g., facial nerve function was improved, unchanged, worsened). Secondary endpoints included postoperative complications and tumor progression, when reported. Postoperative complications were defined as adverse events that occurred as a result of surgical or radiosurgical intervention. Tumor progression was defined as radiographic or symptomatic evidence of residual growth or new recurrence.

\section{Meta-Analysis}

The incidence rate was the primary summary statistics of this study. Incidence was calculated with initial variance by Fisher's exact test for binomial data and then transformed by Freeman-Tukey transformation to stabilize the variances. ${ }^{9}$ All statistics were pooled by meta-analysis of proportions in which the random-effects model described by DerSimonian and Laird ${ }^{10}$ was used to provide the overall incidence statistic. Data are presented as forest plots, where the effect size (ES) of incidence, its $95 \%$ confidence interval (CI), and the relative weightings are represented by the middle of the square, the horizontal line, and the relative size of the square, respectively. Pooled incidence estimates of each functional outcome category were calculated independently and were therefore not necessarily expected to sum to a total of $100 \%$. A random-effects meta-regression using aggregate-level data was used to identify possible trends across the meta-analysis results by time of study publication. Heterogeneity was assessed using $\mathrm{I}^{2}$ for random-effects modeling, with values $>50 \%$ indicating substantial heterogeneity. ${ }^{11}$ Meta-analytical data were presented as forest plots. All $p$ values were twosided, and significance was defined using the alpha threshold 0.05. All statistical analyses were conducted with Stata 14.1 (StataCorp).

\section{Quality and Bias Assessment}

The certainty of each outcome was evaluated using the Grading of Recommendations, Assessment, Development and Evaluations (GRADE) criteria and presented as a summary of findings to identify the certainty of all pooled outcomes. ${ }^{12}$ The quality of evidence for each study was then evaluated using a modified Newcastle-Ottawa Scale $(\mathrm{NOS})^{13}$ for assessment of single-arm cohort studies. ${ }^{14}$ Overall methodological quality was then summarized based on the quality trends observed. In terms of bias for each outcome, when there were $\geq 10$ studies, publication bias was assessed using funnel plots, and small-study biases were evaluated using Egger's linear regression test and Begg's correlation test. ${ }^{15,16}$

\section{Results}

\section{Search Strategy}

The initial search identified 563 references, representing 317 unique studies (Fig. 1). Screening against all selection criteria yielded 74 candidate studies, which underwent full-text analysis. Overall, 33 surgical ${ }^{1,4,17-37}$ and radiosurgical ${ }^{1,5-7,19,38-42}$ studies satisfied inclusion criteria into this study.

\section{Demographics and Clinical Features}

Facial nerve outcomes were reported for 519 patients 


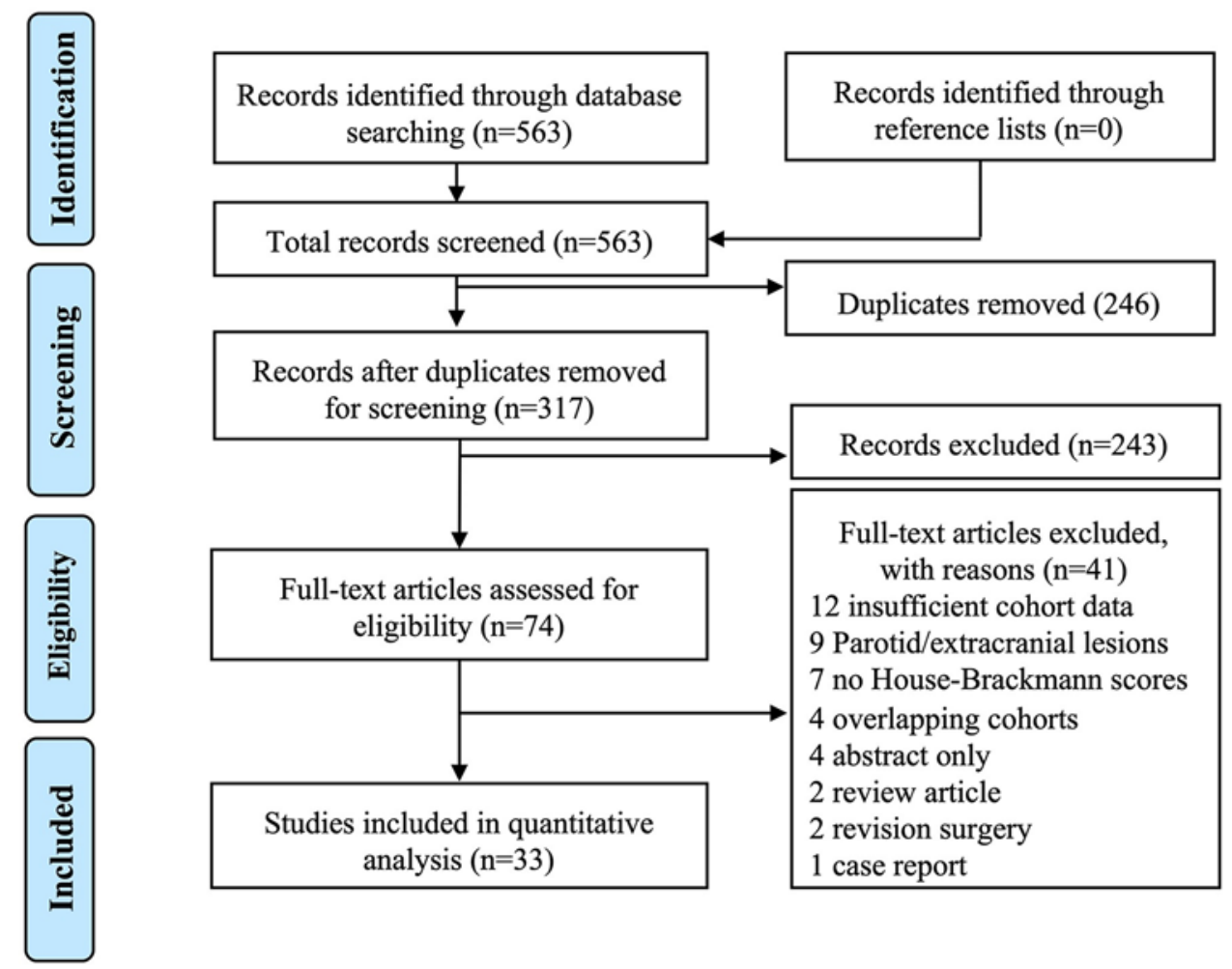

FIG. 1. Results of the PRISMA search strategy. Figure is available in color online only.

with FNS, for whom surgery was the primary treatment in $407(78 \%)$ versus SRS in 112 (22\%) (Table 1).

In the surgical cohorts, the median proportion of females was $55 \%$ (range 33\%-100\%), the median age was 42 years (range 34-63 years), and the median follow-up was 49 months (range 6-122 months) (Table 1). Attempted gross-total resection of the lesion was the most common surgical strategy for FNS (23 studies), whereas other reports included biopsy, decompression, stripping, and nerve root sleeve resection (Table 2). The most common nerves for grafting were the greater auricular and sural nerves, reported in 18 and 17 studies, respectively, with infrequently described graft donor nerves including the hypoglossal and occipital major. The most common coaptation was CN VII-CN XII ( $\mathrm{n}=11$ studies), with other reported procedures including $\mathrm{CN}$ VII-CN VII and $\mathrm{CN}$ VII-CN XI.

In the SRS cohorts, the median proportion of females was $64 \%$ (range $33 \%-79 \%$ ), the median age was 39 years (range 35-50 years), and the median follow-up was 45 months (range 12-81 months) (Table 1).

\section{Facial Nerve Function}

Based on 24 studies, facial nerve function improved following surgical intervention in $23 \%$ (95\% CI $15 \%-$ $32 \%, \mathrm{I}^{2}=71 \%$; P-heterogeneity < 0.01 ); stabilized in $41 \%$ (95\% CI 32\%-50\%, $\mathrm{I}^{2}=61 \%$; P-heterogeneity < 0.01$)$; and worsened in $30 \%$ (95\% CI $21 \%-40 \%, \mathrm{I}^{2}=70 \%$; P-heterogeneity < 0.01) (Fig. 2). In surgical patients with improved postoperative facial nerve function, 73 (74\%) had active facial reanimation during their tumor resection. Based on 10 studies, following SRS intervention facial nerve function improved in $20 \%\left(95 \%\right.$ CI $9 \%-34 \%, \mathrm{I}^{2}=44 \%$; P-heterogeneity $=0.07)$; stabilized in $66 \%(95 \%$ CI $54 \%-78 \%$, $\mathrm{I}^{2}=23 \%$; P-heterogeneity $=0.23$ ); and worsened in $9 \%$ $\left(95 \%\right.$ CI $3 \%-16 \%, \mathrm{I}^{2}=0 \%$; P-heterogeneity $\left.=0.79\right)$ (Fig. 3). Overall, SRS resulted in statistically greater incidence of stable posttreatment facial nerve function (P-interaction $<0.01$ ) and a statistically lower incidence of worsened function (P-interaction < 0.01) compared with resection. There was no statistical difference in improved function incidences between interventions $($ P-interaction $=0.87)$.

\section{Postoperative Complications}

Surgical complications were reported by 10 studies, with an overall incidence of $7 \%\left(95 \%\right.$ CI $1 \%-15 \%, \mathrm{I}^{2}=$ 48\%; P-heterogeneity $=0.05)$, as compared with $4 \%(95 \%$ CI $0 \%-12 \%, I^{2}=0 \%$; P-heterogeneity $=0.43$ ) in 4 studies reporting SRS outcomes (Fig. 4). There was no statistical difference in postoperative complication incidences between interventions (P-interaction $=0.65)$.

\section{Progression}

Posttreatment disease progression was reported in 19 operative studies at an incidence of $2 \%$ (95\% CI 0\%-5\%, $\mathrm{I}^{2}=10 \%$; P-heterogeneity $=0.33$ ), and in 8 SRS studies at an incidence of $3 \%\left(95 \%\right.$ CI $0 \%-11 \%, \mathrm{I}^{2}=39 \%$; P-heterogeneity $=0.12$ ) (Fig. 5). There was no statistical difference in progression incidences between interventions $($ P-interaction $=0.58)$. 
TABLE 1. Design and demographic characteristics of included studies

\begin{tabular}{|c|c|c|c|c|c|c|c|}
\hline \multirow[b]{2}{*}{ Authors \& Year } & \multirow[b]{2}{*}{ Country } & \multirow[b]{2}{*}{ Study Period } & \multirow[b]{2}{*}{ Design* } & \multicolumn{3}{|c|}{ Cohort† } & \multirow{2}{*}{$\begin{array}{c}\text { Mean Follow-Up } \\
\text { (mos) }\end{array}$} \\
\hline & & & & Size (no.) & Females (\%) & Mean Age (yrs) & \\
\hline \multicolumn{8}{|l|}{ Surgery treatment } \\
\hline Bacciu et al., $2014^{17}$ & Italy & $1991-2012$ & R OCS (3) & 23 & 65 & 45 & 18 \\
\hline Carlson et al., $2016^{1}$ & US & $1990-2015$ & R OCS (1) & 34 & NR & 45 & 50 \\
\hline Chung et al., $2004^{18}$ & Korea & $1993-2001$ & R OCS (1) & 8 & 75 & 42 & 39 \\
\hline Doshi et al., $2015^{19}$ & UK & 1994-2013 & R OCS (1) & 16 & NR & 43 & NR \\
\hline Eshraghi et al., $2019^{2}$ & US & $1996-2017$ & R OCS (2) & 27 & NR & NR & NR \\
\hline Günther et al., $2010^{20}$ & Sweden & 1971-2006 & R OCS (1) & 26 & 50 & 36 & 122 \\
\hline Kim \& Suh, $2007^{21}$ & Korea & $1982-2006$ & R OCS (1) & 25 & 72 & 36 & 76 \\
\hline Kohmura et al., $2007^{22}$ & Japan & $1988-2004$ & R OCS (1) & 6 & 33 & 52 & NR \\
\hline Lahlou et al., $2016^{23}$ & France & $1988-2013$ & R OCS (1) & 19 & NR & NR & 50 \\
\hline Lee et al., $2007^{24}$ & Korea & 1996-2005 & R OCS (1) & 6 & 33 & 34 & 53 \\
\hline Li \& Dai, $2017^{25}$ & China & $1988-2008$ & R OCS (1) & 15 & 53 & 34 & 84 \\
\hline Liu \& Fagan, $2001^{26}$ & Australia & $1982-2000$ & R OCS (1) & 12 & 50 & 42 & 31 \\
\hline Lu et al., $2015^{27}$ & China & NR & R OCS (1) & 17 & 53 & 36 & 44 \\
\hline McMonagle et al., $2008^{28}$ & Australia & $1985-2005$ & R OCS (2) & 33 & 33 & 47 & NR \\
\hline Minovi et al., $2004^{29}$ & Germany & 1989-2004 & R OCS (1) & 11 & NR & 53 & 34 \\
\hline Mowry et al., $2012^{30}$ & US & $1998-2010$ & R OCS (1) & 14 & 71 & 50 & 12 \\
\hline Nadeau \& Sataloff, $2003^{31}$ & US & 1983-1996 & R OCS (1) & 7 & 71 & 49 & 82 \\
\hline Park et al., $2014^{32}$ & Korea & $1995-2013$ & R OCS (1) & 28 & 50 & 42 & 60 \\
\hline Perez et al., $2005^{4}$ & Canada & $1979-2004$ & R OCS (1) & 11 & 45 & 38 & 99 \\
\hline Sherman et al., $2002^{33}$ & US & 1991-1997 & R OCS (1) & 10 & 60 & 47 & 33 \\
\hline Shirazi et al., $2007^{34}$ & US & $1990-2006$ & R OCS (1) & 16 & 56 & 46 & 36 \\
\hline Sun et al., $2015^{35}$ & China & 2000-2009 & R OCS (1) & 18 & 56 & 36 & 70 \\
\hline West et al., $2018^{36}$ & Denmark & NR & R OCS (1) & 3 & 100 & 63 & 6 \\
\hline Xiang et al., $2015^{37}$ & China & NR & R OCS (1) & 19 & 58 & 36 & 86 \\
\hline \multicolumn{8}{|l|}{ Radiosurgery treatment } \\
\hline Carlson et al., $2016^{1}$ & US & $1990-2015$ & R OCS (1) & 13 & NR & NR & NR \\
\hline Comps et al., $2018^{38}$ & Switzerland & $2010-2017$ & R OCS (1) & 4 & 75 & 44 & 39 \\
\hline Eshraghi et al., $2019^{2}$ & US & $1996-2017$ & R OCS (2) & 9 & NR & NR & NR \\
\hline Fezeu et al., $2015^{7}$ & US & $2005-2013$ & R OCS (1) & 5 & 40 & 35 & 12 \\
\hline Hasegawa, $2013^{39}$ & Japan & $1991-2013$ & R OCS (10) & 42 & 79 & 50 & 48 \\
\hline Litre et al., $2007^{6}$ & France & $1992-2003$ & P OCS (1) & 11 & 64 & 46 & 39 \\
\hline Madhok et al., $2009^{40}$ & US & NR & R OCS (1) & 6 & 33 & 39 & 47 \\
\hline McRackan et al., $2015^{41}$ & US & $1995-2014$ & R OCS (1) & 7 & NR & NR & 57 \\
\hline Moon et al., $2014^{5}$ & Korea & $2000-2012$ & R OCS (1) & 14 & 57 & 37 & 81 \\
\hline Shi et al., $2016^{42}$ & US & $1998-2011$ & R OCS (1) & 8 & 75 & 39 & 43 \\
\hline
\end{tabular}

$\mathrm{NR}=$ not reported; $\mathrm{OCS}=$ observational cohort study; $\mathrm{P}=$ prospective; $\mathrm{R}=$ retrospective.

* The number of institutions is in parentheses.

† These numbers reflect cohorts that were treated by the listed modality. Many studies reported a conservative management arm in their cohorts, which were not included in this analysis.

\section{Quality and Certainty Assessment}

On GRADE criteria, the certainty of all outcomes ranged from very low to moderate (Table 3 ). In the surgical intervention group, stable facial nerve function was rated low certainty, whereas all other outcomes were rated very low certainty. In the SRS group, stable facial nerve function was rated moderate certainty, with the remaining outcomes rated low certainty. According to Meta-Analysis of Observational Studies in Epidemiology (MOOSE) cri- teria, all included studies were deemed to be of good quality to answer our targeted PICOS question (Supplemental Table 1).

\section{Bias Assessment}

Funnel plots generated for outcomes with $\geq 10$ studies did not demonstrate significant asymmetry, indicating low likelihood of publication bias in our outcomes. Linear regression by Begg's and Egger's tests for outcomes with 
TABLE 2. Clinical features and outcomes of all included studies

\begin{tabular}{|c|c|c|c|c|c|c|}
\hline \multirow[b]{2}{*}{ Authors \& Year } & \multicolumn{2}{|c|}{ Operative Data } & \multicolumn{2}{|c|}{ Mean HB Scores } & \multicolumn{2}{|l|}{ Postop Course } \\
\hline & $\begin{array}{c}\text { Surgical } \\
\text { Approach(es) }\end{array}$ & $\begin{array}{c}\text { Graft(s)/ } \\
\text { Anastomoses Used }\end{array}$ & Preop & Postop & $\begin{array}{l}\text { No. of Complications } \\
\text { (breakdown, description) }\end{array}$ & $\begin{array}{l}\text { Recurrence } \\
\text { (no.) }\end{array}$ \\
\hline \multicolumn{7}{|l|}{ Surgery treatment } \\
\hline Bacciu et al., $2014^{17}$ & Resection, decompression & Sural, GAN/CN VII-XII & 1.6 & 2.2 & NR & NR \\
\hline Carlson et al., $2016^{1}$ & Resection, decompression & $\begin{array}{r}\text { Sural, GAN/CN VII-XII, } \\
\text { CN VII-XI, CN VII-V }\end{array}$ & 1.9 & 2.7 & NR & 15 \\
\hline Chung et al., $2004^{18}$ & Resection, parotidectomy & Sural, GAN/CN VII-XII & 4.0 & 3.8 & 3 (2 wounds, 1 nerve damage) & 0 \\
\hline Doshi et al., $2015^{19}$ & NR & Sural, GAN/CN VII-XII & 2.0 & 1.9 & 4 (4 CSF leaks) & 0 \\
\hline Eshraghi et al., $2019^{2}$ & Resection & NR & 2.3 & 3.3 & NR & NR \\
\hline Günther et al., $2010^{20}$ & Resection & Sural, GAN/CN VII-XI & 3.2 & 3.5 & $\begin{array}{l}3 \text { (1 CSF leak, } 1 \text { infection, } 1 \\
\text { nerve damage) }\end{array}$ & 8 \\
\hline Kim \& Suh, $2007^{21}$ & NR & Sural, GAN/CN VII-XII & & & NR & 0 \\
\hline Kohmura et al., $2007^{22}$ & Resection & Sural & 2.0 & 2.8 & NR & NR \\
\hline Lahlou et al., $2016^{23}$ & Resection & Sural, GAN/CN VII-VII & 3.0 & 3.0 & 1 (1 hematoma) & 5 \\
\hline Lee et al., $2007^{24}$ & Resection, decompression & None & 1.3 & 1.7 & NR & 0 \\
\hline Li \& Dai, $2017^{25}$ & Resection & None & 1.9 & 1.7 & NR & 27 \\
\hline Liu \& Fagan, $2001^{26}$ & $\begin{array}{l}\text { Resection, decompres- } \\
\text { sion, biopsy }\end{array}$ & Sural, GAN/CN VII-XII & 4.2 & 4.0 & NR & 0 \\
\hline Lu et al., $2015^{27}$ & Stripping, resection & Sural, GAN & 5.5 & 3.9 & NR & 0 \\
\hline McMonagle et al., $2008^{28}$ & $\begin{array}{l}\text { Resection, decompres- } \\
\text { sion, biopsy }\end{array}$ & $\begin{array}{l}\text { Sural, GAN/CN VII-XII, } \\
\text { CN VII-VII }\end{array}$ & 2.6 & 3.0 & $\begin{array}{l}6 \text { (1 infection, } 1 \text { CSF leak, } 1 \\
\text { HA/tinnitus, } 1 \text { vertigo, } 1 \text { tongue } \\
\text { atrophy, } 1 \text { EAC stenosis) }\end{array}$ & 6 \\
\hline Minovi et al., $2004^{29}$ & Resection & Sural, GAN/CN VII-XII & 2.4 & 3.3 & 0 & 0 \\
\hline Mowry et al., $2012^{30}$ & Resection, decompression & NR & 1.0 & 1.4 & NR & 7 \\
\hline Nadeau \& Sataloff, $2003^{31}$ & Resection & GAN/CN VII-VIII & 1.3 & 3.1 & NR & 0 \\
\hline Park et al., $2014^{32}$ & Stripping, resection & $\begin{array}{l}\text { Sural, GAN/CN VII-XII, } \\
\text { CN VII-VII }\end{array}$ & 2.5 & 2.8 & NR & 0 \\
\hline Perez et al., $2005^{4}$ & Resection & $\begin{array}{l}\text { Sural, GAN/CN VII-XII, } \\
\text { CN VII-VII }\end{array}$ & 3.6 & 2.9 & NR & 0 \\
\hline Sherman et al., $2002^{33}$ & Resection & Sural, GAN & 3.0 & 2.3 & 0 & 0 \\
\hline Shirazi et al., $2007^{34}$ & Resection, decompression & Sural, GAN/CN VII-XII & 3.6 & 3.0 & 0 & 0 \\
\hline Sun et al., $2015^{35}$ & Stripping, decompression & NR & 2.3 & 2.2 & NR & 0 \\
\hline West et al., $2018^{36}$ & Resection & None & 2.0 & 2.7 & 0 & 0 \\
\hline Xiang et al., $2015^{37}$ & Resection & Sural, GAN & 2.2 & 2.3 & 0 & 0 \\
\hline \multicolumn{7}{|l|}{ Radiosurgery treatment } \\
\hline Carlson et al., $2016^{1}$ & & NA & 1.3 & 1.5 & NR & 31 \\
\hline Comps et al., $2018^{38}$ & & NA & 3.0 & 2.6 & 0 & NR \\
\hline Eshraghi et al., $2019^{2}$ & & NA & 2.3 & 1.7 & NR & NR \\
\hline Fezeu et al., $2015^{7}$ & & NA & 3.2 & 2.6 & NR & 0 \\
\hline Hasegawa, $2013^{39}$ & & NA & 2.7 & 2.6 & $\begin{array}{l}5 \text { ( } 3 \text { nerve palsies, } 1 \mathrm{HA} / \text { tin- } \\
\text { nitus, } 1 \text { vertigo) }\end{array}$ & 2 \\
\hline Litre et al., $2007^{6}$ & & NA & 2.0 & 2.5 & NR & 9 \\
\hline Madhok et al., $2009^{40}$ & & NA & 2.7 & 2.5 & 0 & 0 \\
\hline McRackan et al., $2015^{41}$ & & NA & NA & NA & NR & NR \\
\hline Moon et al., $2014^{5}$ & & NA & 2.6 & 2.5 & 0 & 0 \\
\hline Shi et al., $2016^{42}$ & & NA & 2.3 & 1.8 & NR & 0 \\
\hline
\end{tabular}

$\mathrm{EAC}=$ external auricular canal; $\mathrm{GAN}=$ great auricular nerve; $\mathrm{HA}=$ headache; $\mathrm{NA}=$ not applicable. 
Rotter et al.

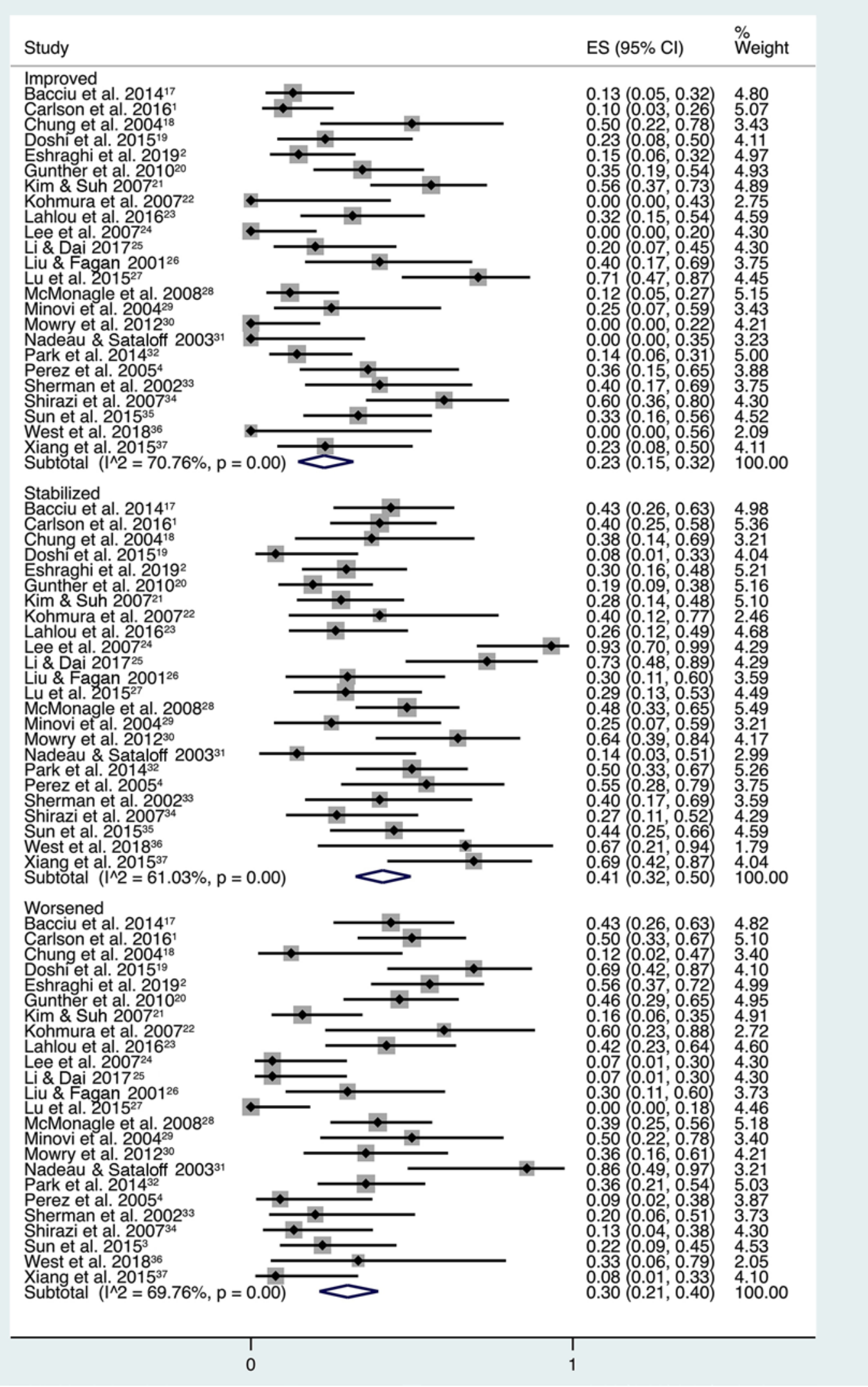

FIG. 2. Forest plot of incidence of facial nerve function (ES) following surgical intervention. Figure is available in color online only. 


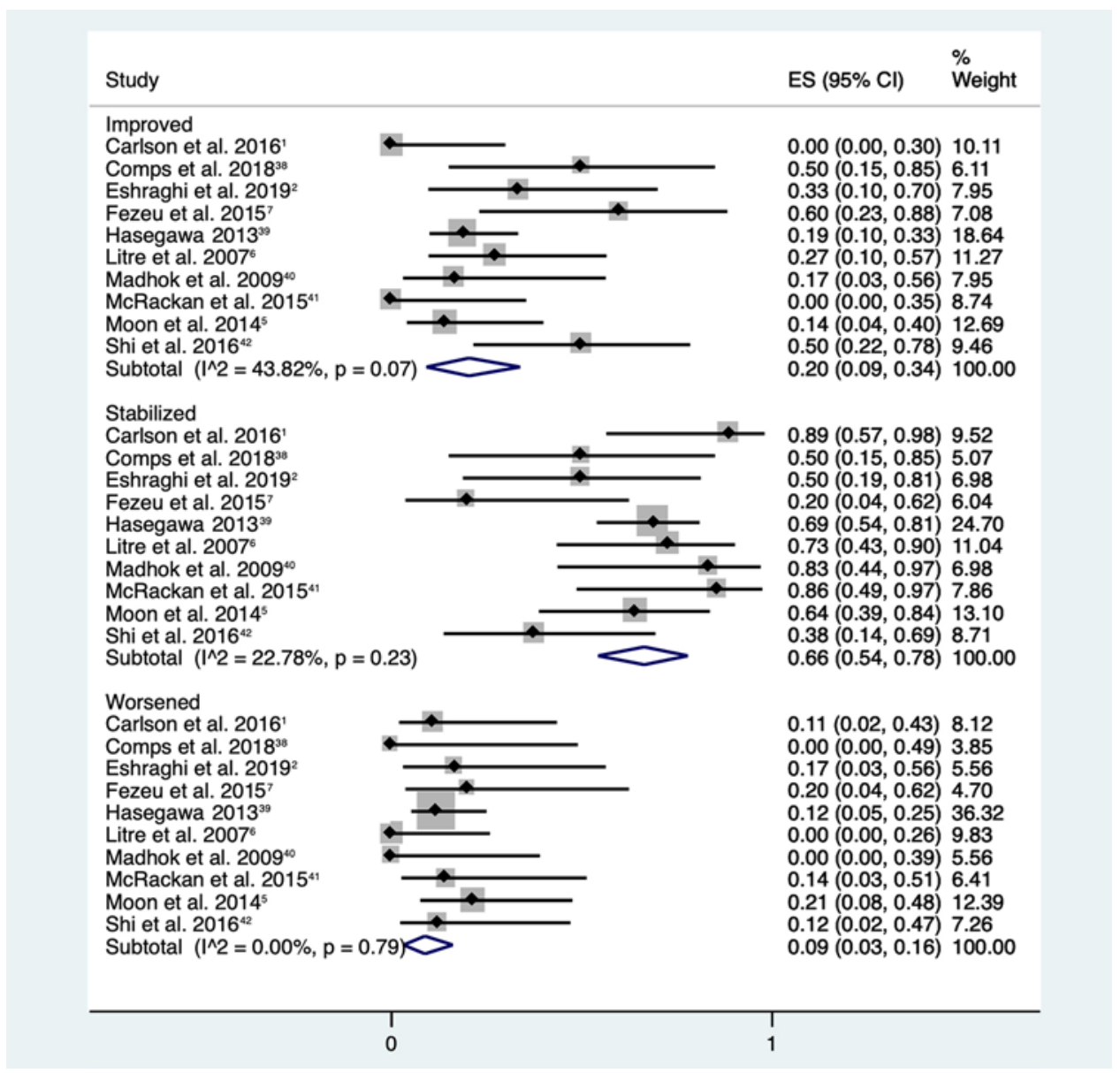

FIG. 3. Forest plot of incidence of facial nerve function (ES) following radiosurgical intervention. Figure is available in color online only.

$\geq 10$ studies did not yield statistically significant results, indicating a low likelihood of small-study bias.

\section{Trends Over Time}

There were no linear trends related to time concerning the pretreatment HB score for either the surgical cohort (slope $=-0.02, p=0.58$ ) or the radiosurgery cohort (slope $=0.01, \mathrm{p}=0.83$ ). Furthermore, meta-regression did not identify any statistically significant trends across time for any of the tiers of facial nerve function outcome for the surgery or radiosurgery cohorts (Supplemental Table 2).

\section{Discussion}

We report the first systematic review and meta-analysis comparing facial nerve outcomes after resection or SRS for patients with FNS; this study was conducted in order to better inform treatment recommendations and decisionmaking. Based on the current study, significantly more patients appear to have stable facial nerve function after SRS, whereas unfavorable facial nerve outcomes are significantly associated with surgical treatment. These findings will assist clinicians and patients alike in assessing the risks and benefits of treatment for FNS.

Across all studies and independent of treatment strategy, the estimated summary effects in the current study suggest that approximately 1 in 5 patients will experience improved facial nerve function (i.e., reduced HB scores) after treatment, although the consistency between studies did vary significantly. ${ }^{2,7,27}$ It is important to note that improvements after surgery are probably attributable to reanimation instead of direct changes to or decompression of the facial nerve, and the degree to which this occurs probably varies intrinsically within each study. Although our findings provide some limited encouragement for those patients presenting with marked facial weakness at baseline, it is likely to be less pertinent to the majority of patients, for whom the threat of losing normal or near-normal facial nerve function is far more salient than the potential for recovery. Correspondingly, we anticipate that qualitative, directional approximations of facial nerve outcome will be more useful in the patient education and counseling setting.

In the setting of FNS, many surgeons would recommend watchful waiting to patients with minimal degradation in facial function; radiosurgery for moderate reduction in facial function; and surgery for poor facial function (HB IV or worse) or for significant mass effect. Stratifying patients based on clinical symptoms may result in underlying tumor-specific differences and biases among the co- 


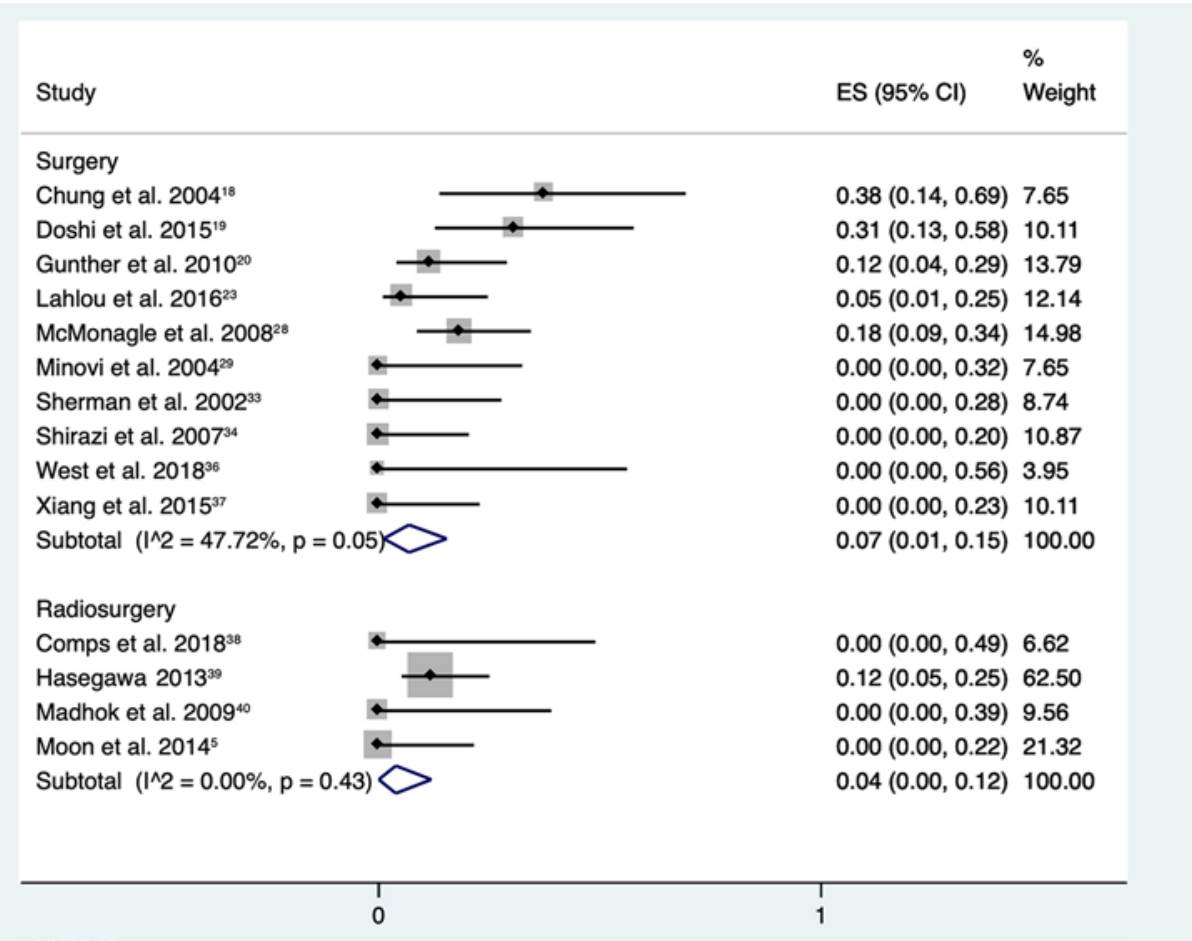

FIG. 4. Forest plot of incidence of postoperative complications (ES) following surgical versus radiosurgical intervention. Figure is available in color online only.

hort outcomes that could account for posttreatment facial function trends. We do recognize that, because radiosurgery and watchful waiting are relatively newer therapeutic strategies, the earlier surgical cohorts probably included patients who would have otherwise undergone a different treatment modality. Still, our meta-regression did not detect a significant trend toward bias with time of study publication, which is encouraging for the interpretability of our results.

Based on our findings and the preceding literature, SRS appears to be significantly associated with a larger proportion of patients emerging from treatment with stable facial nerve function, as compared with those undergoing surgery. ${ }^{1,43}$ Put another way, the current study empowers clinicians to relate one of the most potentially meaningful treatment parameters-facial nerve stability-to patients and colleagues with the highest degree of certainty, based on the presently available literature. By the same token, the companion risk of worsened facial nerve function is also highly salient to patients, which we noted to be significantly associated with surgery. ${ }^{44}$ Candidly, given that most studies of SRS reported essentially a zero incidence of degraded facial function, the differences observed in outcome may be predominantly driven by unfavorable outcomes following surgery, rather than favorable outcomes following SRS. $5,6,38,40$

We did not identify a statistically significant difference in the incidence of complications, which ranged from $4 \%$ to $7 \%$, or risk of progression, which ranged from $2 \%$ to $3 \%$ across all included studies, although the certainty of these findings is low. With respect to complications, we do note that, looking more broadly at the literature comparing out- comes after SRS and surgery, treatment-related morbidity and complications are almost universally lower following radiosurgery. ${ }^{45-50}$ Indeed, due to probable underreporting, it would be difficult to conclude with a high degree of certainty that there was no difference in complication rates after surgery or SRS, and this finding should be interpreted with caution when discussing with patients.

Although it is possible that the present study is insufficiently powered to detect a true difference in the risk of progression between surgery and SRS for FNS, other factors are likely to be more clinically relevant when counseling patients regarding treatment decision-making. Accordingly, we recommend de-emphasizing efficacy, or risk of tumor progression, when counseling patients with FNS, in order to focus on the well-described differences in risk profiles between the treatment options. Of particular interest, the majority of the postsurgical recurrences observed did arise following partial resection or biopsy, a finding that accords with the VS literature. ${ }^{51,52}$ However, given the low estimated absolute incidence rate of treatment failure and the significant increase in risk of an adverse facial nerve outcome following gross-total resection of FNS, we do not explicitly advocate for aggressive resection, but individualize treatment planning and patient counseling with regard to the individual anatomy, goals, and risk tolerance, with consideration given to primary SRS or adjuvant SRS following subtotal resection, as well as the rare pursuit of gross-total resection in carefully selected individuals. ${ }^{32,53}$

Several unanswered questions anticipate future research. With respect to clinical practice, although watchful waiting often precedes treatment of FNS at initial 


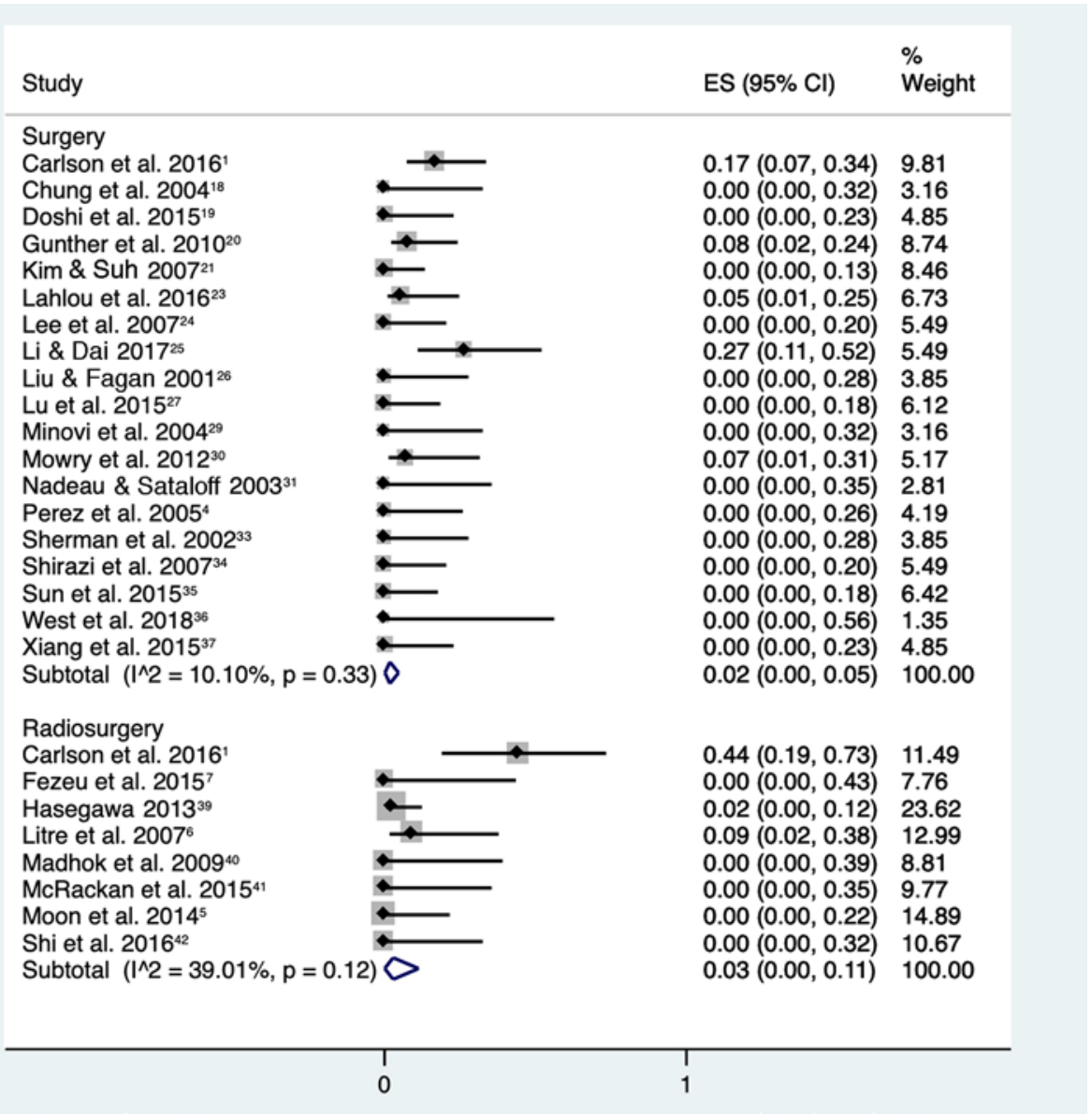

FIG. 5. Forest plot of incidence of progression (ES) following surgical versus radiosurgical intervention. Figure is available in color online only.

detection, optimal treatment timing has not yet been established. Because SRS confers the highest incidence of stable facial nerve function, with excellent tumor control and a very low incidence of complications, the current study results would support consideration of SRS as the predominant first-line treatment for symptomatic FNS. Furthermore, given the potential for successful long-term treatment of small FNS via SRS, one could advocate for consideration of earlier and more aggressive treatment of asymptomatic or minimally symptomatic FNS via SRS, in hopes of reducing the incidence of patients developing either more severe symptoms or sufficient tumor growth that resection would be mandatory.

\section{Strength and Limitations}

By adhering to PRISMA guidelines and using a robust search strategy, the literature search completed within the current study was comprehensive and reproducible. The PRISMA checklist served as an internal assessment tool to optimize conclusion quality and minimize bias. Using a random-effects model will have somewhat reduced the interstudy heterogeneity, improving the robustness of our findings.

There are limitations to be addressed by future studies. Outside the standard call for increased cohort size and statistical power, we note that all studies were retrospective, save for the prospective study by Litre et al. ${ }^{6}$ Due to inherent clinical heterogeneity that is difficult to ascertain in retrospect, unanalyzed clinical and patient factors that guided treatment timing, strategy, technique, and need for additional management may have confounded our results. The current literature is limited by a lack of granularity with respect to tumor diagnosis methods; therefore, it is possible that we included misclassified VS or hemangioma cases, and excluded patients with unreported, misdiagnosed FNS. Other insights into managing this and other clinically meaningful nuances, such as the decision to use specific surgical approaches for resection, and detailed SRS parameters, such as biological effective dose, are also precluded by this type of analysis. ${ }^{32,54-56} \mathrm{~A}$ more detailed comparison of individual surgical techniques was not possible due to the limitations of the available data and associated implications for statistical power. The comparably low incidences of complication may be more attributable to the lack of reported complications rather than to a nonstatistically significant difference between the complication incidences of the two cohorts. Furthermore, this analysis does not account for differences in complication type-surgical patients, unlike SRS patients, are at increased risk for infection, clots, and focal 
TABLE 3. GRADE assessment for reported outcomes

\begin{tabular}{|c|c|c|c|c|c|c|c|c|c|}
\hline \multirow[b]{2}{*}{ Outcome } & \multirow{2}{*}{$\begin{array}{l}\text { Pooled Incidence } \\
\qquad(95 \% \mathrm{Cl})\end{array}$} & \multirow{2}{*}{$\begin{array}{l}\text { No. of Cohorts } \\
\text { (studies) }\end{array}$} & \multicolumn{5}{|c|}{ Certainty Assessment } & \multirow{2}{*}{$\begin{array}{l}\text { Overall } \\
\text { Quality }\end{array}$} & \multirow[b]{2}{*}{ Certainty } \\
\hline & & & Type of Evidence & Quality & Consistency & Directness & ES & & \\
\hline \multicolumn{10}{|l|}{ Surgical intervention } \\
\hline \multicolumn{10}{|l|}{ Facial nerve function } \\
\hline Improved & $23 \%(15-32 \%)$ & 24 & +2 & -1 & 0 & 0 & 0 & +1 & Very low \\
\hline Stable & $41 \%(32-50 \%)$ & 24 & +2 & -1 & 0 & 0 & +1 & +2 & Low \\
\hline Worsened & $30 \%(21-40 \%)$ & 24 & +2 & -1 & 0 & 0 & 0 & +1 & Very low \\
\hline Postop complications & $7 \%(1-15 \%)$ & 10 & +2 & -1 & -1 & 0 & +1 & +1 & Very low \\
\hline Progression & $2 \%(0-5 \%)$ & 19 & +2 & -1 & 0 & 0 & 0 & +1 & Very low \\
\hline \multicolumn{10}{|l|}{ Radiosurgical intervention } \\
\hline \multicolumn{10}{|l|}{ Facial nerve function } \\
\hline Improved & $20 \%(9-34 \%)$ & 10 & +2 & -1 & 0 & 0 & +1 & +2 & Low \\
\hline Stable & $66 \%(54-78 \%)$ & 10 & +2 & -1 & 0 & 0 & +2 & +3 & Moderate \\
\hline Worsened & $9 \%(3-16 \%)$ & 10 & +2 & -1 & 0 & 0 & +1 & +2 & Low \\
\hline Postop complications & $4 \%(0-12 \%)$ & 4 & +2 & -1 & 0 & 0 & +1 & +2 & Low \\
\hline Progression & $3 \%(0-11 \%)$ & 8 & +2 & -1 & 0 & 0 & +1 & +2 & Low \\
\hline
\end{tabular}

The overall quality score is determined based on the sum of the included domains. Type of evidence is based on the design of the included studies (range +2 to +4 ). The study quality reflects the blinding and allocation, follow-up and withdrawals, sparsity of data, and methodological concerns (range -3 to 0 ). Consistency is graded based on the heterogeneity of the included population and study endpoints with respect to one another (range -1 to +1 ). Directness is graded based on the generalizability of the included results (range -2 to 0 ). Effect size is graded based on the overlap of the $95 \% \mathrm{Cl}$ estimates within $10 \%$ of either $0 \%$ or $100 \%$ incidence (range 0 to 2 ). The overall quality of results for each outcome can be considered high ( $\geq 4$ points), moderate ( 3 points), low ( 2 points), or very low ( $\leq 1$ point).

neurological deficits; even within the surgical cohort, each surgical strategy carries a unique risk for specific complications.

Additionally, although the HB scoring system is a relatively standardized metric, the inconsistencies in interrater reliability, which are well described, compromise an idealized analysis of facial nerve function outcomes. ${ }^{57}$ Therefore, given the heterogeneous nature of the studies and centers represented by the present meta-analysis, we collapsed the subjectively assigned numeric HB values, which are more vulnerable to bias, into more reliable and clinically relevant categories of worsened, stabilized, or improved. Additionally, because the HB scores do not fully communicate the nuances of degraded facial function, Fattah et al. recommended the widespread adoption of the Sunnybrook Facial Grading Scale after comparing the convenience in clinical practice, reproducibility, variability, sensitivity, and several other factors of 19 facial nerve grading scales, including HB. ${ }^{58,59}$ Most facial grading scales lack the resolution necessary to report zonal changes in response to reanimation, which led to the development of computer applications like eFACE; however, these tools are neither convenient nor practical for widespread clinical use. ${ }^{58}$

Finally, we recognize that facial nerve function is one of numerous outcomes that may influence individual clinician or patient decisions, including whether to pursue treatment at all, to say nothing of the determination between resection or SRS. The more favorable long-term prognosis of these tumors places a greater emphasis on optimizing patient outcomes, for which other parameters such as aesthetic outcome and recovery time may also significantly impact decision-making in a way that cannot be detected based on the available data. Unfortunately, com- pared with quality-of-life data reported in VS, direct data reporting pertinent outcomes in FNS are very limited at present. $.55,60-62$

\section{Conclusions}

In this study we conducted a systematic, metadatabased analysis of the existing literature on facial nerve outcomes after surgery or SRS in patients with FNS. We report differences in stable and worsened facial function outcomes based on changes between preoperative and final postoperative HB scores. SRS appears to be associated with a significantly higher incidence of stable facial nerve function, as well as with the greatest certainty in the observed effect; in contrast, surgery appears to be associated with a higher incidence of worsened facial nerve function. These results suggest that SRS should be considered the front-line option in patients with FNS who require treatment in order to preserve their facial function. In contrast, resection should be reserved for patients who require treatment of their FNS and have a separate indication for surgery, such as decompression of the brainstem, establishment of a diagnosis, or treatment of hydrocephalus. Further research should investigate this possibility in a more robust and rigorous fashion, as well as the question of optimal treatment timing with respect to symptomatic onset.

\section{Appendix \\ Query Translation}

("facial nerve schwannoma"[All Fields] OR "facial schwannoma"[All Fields]) AND ((“surgery"[Subheading] OR "surgery"[All Fields] OR "surgical procedures, operative"[MeSH Terms] OR ("surgical”[All Fields] AND “procedures"[All 
Fields] AND “operative"[All Fields]) OR “operative surgical procedures"[All Fields] OR “surgery”[All Fields] OR "general surgery"[MeSH Terms] OR ("general"[All Fields] AND "surgery"[All Fields]) OR "general surgery"[All Fields]) OR (“radiosurgery”[MeSH Terms] OR “radiosurgery”[All Fields]))

\section{MeSH Translations}

\section{Surgery}

"surgery"[Subheading] OR "surgery"[All Fields] OR "surgical procedures, operative"[MeSH Terms] OR ("surgical"[All Fields] AND "procedures"[All Fields] AND "operative"[All Fields]) OR "operative surgical procedures"[All Fields] OR "surgery"[All Fields] OR "general surgery"[MeSH Terms] OR ("general"[All Fields] AND "surgery”[All Fields]) OR "general surgery"[All Fields]

\section{Radiosurgery}

“radiosurgery”[MeSH Terms] OR “radiosurgery”[All Fields]

\section{References}

1. Carlson ML, Deep NL, Patel NS, et al. Facial nerve schwannomas: review of 80 cases over 25 years at Mayo Clinic. Mayo Clin Proc. 2016;91(11):1563-1576.

2. Eshraghi AA, Oker N, Ocak E, et al. Management of facial nerve schwannoma: a multicenter study of 50 cases. J Neurol Surg B Skull Base. 2019;80(4):352-356.

3. McRackan TR, Rivas A, Wanna GB, et al. Facial nerve outcomes in facial nerve schwannomas. Otol Neurotol. 2012;33(1): 78-82. Published correction in Otol Neurotol. 2012;33(3):472.

4. Perez R, Chen JM, Nedzelski JM. Intratemporal facial nerve schwannoma: a management dilemma. Otol Neurotol. 2005; 26(1):121-126.

5. Moon JH, Chang WS, Jung HH, et al. Gamma Knife surgery for facial nerve schwannomas. J Neurosurg. 2014;121(suppl): $116-122$.

6. Litre CF, Gourg GP, Tamura M, et al. Gamma knife surgery for facial nerve schwannomas. Neurosurgery. 2007;60(5): 853-859.

7. Fezeu F, Lee CC, Dodson BK, et al. Stereotactic radiosurgery for facial nerve schwannomas: a preliminary assessment and review of the literature. Br J Neurosurg. 2015;29(2):213-218.

8. Moher D, Liberati A, Tetzlaff J, Altman DG. Preferred reporting items for systematic reviews and meta-analyses: the PRISMA statement. PLoS Med. 2009;6(7):e1000097.

9. Freeman MF, Tukey JW. Transformations related to the angular and the square root. Ann Math Stat. 1950;21(4): 607-611.

10. DerSimonian R, Laird N. Meta-analysis in clinical trials. Control Clin Trials. 1986;7(3):177-188.

11. Higgins JPT, Thompson SG, Deeks JJ, Altman DG. Measuring inconsistency in meta-analyses. BMJ. 2003;327(7414): $557-560$.

12. Atkins D, Best D, Briss PA, et al. Grading quality of evidence and strength of recommendations. BMJ. 2004;328(7454):1490.

13. Wells G, Shea B, O'Connell D, et al. The Newcastle-Ottawa Scale (NOS) for Assessing the Quality of Nonrandomised Studies in Meta-Analyses. Ottawa Hospital Research Institute; 2016.

14. Murad MH, Sultan S, Haffar S, Bazerbachi F. Methodological quality and synthesis of case series and case reports. $B M J$ Evid Based Med. 2018;23(2):60-63.

15. Begg CB, Mazumdar M. Operating characteristics of a rank correlation test for publication bias. Biometrics. 1994;50(4): 1088-1101.

16. Egger M, Davey Smith G, Schneider M, Minder C. Bias in meta-analysis detected by a simple, graphical test. $B M J$. 1997;315(7109):629-634.
17. Bacciu A, Medina M, Ben Ammar M, et al. Intraoperatively diagnosed cerebellopontine angle facial nerve schwannoma: how to deal with it. Ann Otol Rhinol Laryngol. 2014;123(9): 647-653.

18. Chung JW, Ahn JH, Kim JH, et al. Facial nerve schwannomas: different manifestations and outcomes. Surg Neurol. 2004;62(3):245-252, 452.

19. Doshi J, Heyes R, Freeman SR, et al. Clinical and radiological guidance in managing facial nerve schwannomas. Otol Neurotol. 2015;36(5):892-895.

20. Günther M, Danckwardt-Lillieström N, Gudjonsson O, et al. Surgical treatment of patients with facial neuromas - a report of 26 consecutive operations. Otol Neurotol. 2010;31(9): 1493-1497.

21. Kim CS, Suh MW. Skull base surgery for removal of temporal bone tumors. Acta Otolaryngol Suppl. 2007;(558):4-14.

22. Kohmura E, Aihara H, Miyake S, Fujita A. Intradural facial nerve schwannoma: diagnostic and therapeutic problems. Skull Base. 2007;17(3):215-222.

23. Lahlou G, Nguyen Y, Russo FY, et al. Intratemporal facial nerve schwannoma: clinical presentation and management. Eur Arch Otorhinolaryngol. 2016;273(11):3497-3504.

24. Lee JD, Kim SH, Song MH, et al. Management of facial nerve schwannoma in patients with favorable facial function. Laryngoscope. 2007;117(6):1063-1068.

25. Li Y, Dai C. A retrospective study on facial nerve schwannomas: a disease with a high risk of misdiagnosis and hearing loss. Eur Arch Otorhinolaryngol. 2017;274(9): 3359-3366.

26. Liu R, Fagan P. Facial nerve schwannoma: surgical excision versus conservative management. Ann Otol Rhinol Laryngol. 2001;110(11):1025-1029.

27. Lu R, Li S, Zhang L, et al. Stripping surgery in intratemporal facial nerve schwannomas with poor facial nerve function. Am J Otolaryngol. 2015;36(3):338-341.

28. McMonagle B, Al-Sanosi A, Croxson G, Fagan P. Facial schwannoma: results of a large case series and review. J Laryngol Otol. 2008;122(11):1139-1150.

29. Minovi A, Vosschulte R, Hofmann E, et al. Facial nerve neuroma: surgical concept and functional results. Skull Base. 2004;14(4):195-201.

30. Mowry S, Hansen M, Gantz B. Surgical management of internal auditory canal and cerebellopontine angle facial nerve schwannoma. Otol Neurotol. 2012;33(6):1071-1076.

31. Nadeau DP, Sataloff RT. Fascicle preservation surgery for facial nerve neuromas involving the posterior cranial fossa. Otol Neurotol. 2003;24(2):317-325.

32. Park SH, Kim J, Moon IS, Lee WS. The best candidates for nerve-sparing stripping surgery for facial nerve schwannoma. Laryngoscope. 2014;124(11):2610-2615.

33. Sherman JD, Dagnew E, Pensak ML, et al. Facial nerve neuromas: report of 10 cases and review of the literature. Neurosurgery. 2002;50(3):450-456.

34. Shirazi MA, Leonetti JP, Marzo SJ, Anderson DE. Surgical management of facial neuromas: lessons learned. Otol Neurotol. 2007;28(7):958-963.

35. Sun Y, Xing B, Han S, et al. Stripping surgery in facial nerve schwannomas with favorable facial nerve function. Am J Otolaryngol. 2015;36(4):513-516.

36. West N, Sass H, Møller MN, Cayé-Thomasen P. Facial nerve schwannomas presenting with vestibular dysfunction: a case series. Acta Neurochir (Wien). 2018;160(12):2315-2319.

37. Xiang D, Liu L, Li Y, Qiao J. Near-total removal of facial nerve schwannomas: long-term outcomes. Am J Otolaryngol. 2015;36(3):390-392.

38. Comps JN, Tuleasca C, Goncalves-Matoso B, et al. Upfront Gamma Knife surgery for facial nerve schwannomas: retrospective case series analysis and systematic review. Acta Neurochir (Wien). 2018;160(5):987-996. 
39. Hasegawa T. Stereotactic radiosurgery for nonvestibular schwannomas. Neurosurg Clin N Am. 2013;24(4):531-542.

40. Madhok R, Kondziolka D, Flickinger JC, Lunsford LD. Gamma knife radiosurgery for facial schwannomas. Neurosurgery. 2009;64(6):1102-1105.

41. McRackan TR, Wilkinson EP, Brackmann DE, Slattery WH. Stereotactic radiosurgery for facial nerve schwannomas: meta-analysis and clinical review. Otol Neurotol. 2015;36(3): 393-398.

42. Shi W, Jain V, Kim H, et al. Fractionated stereotactic radiotherapy for facial nerve schwannomas. J Neurol Surg B Skull Base. 2016;77(1):75-80.

43. Li Y, Liu H, Cheng Y. Subtotal resection of facial nerve schwannoma is not safe in the long run. Acta Otolaryngol. 2014;134(4):433-436.

44. Chong KW, Chung YF, Khoo ML, et al. Management of intraparotid facial nerve schwannomas. Aust N Z J Surg. 2000; 70(10):732-734.

45. Carlson ML, Tveiten OV, Driscoll CL, et al. Long-term quality of life in patients with vestibular schwannoma: an international multicenter cross-sectional study comparing microsurgery, stereotactic radiosurgery, observation, and nontumor controls. J Neurosurg. 2015;122(4):833-842.

46. Carlson ML, Tveiten OV, Lund-Johansen M, et al. Patient motivation and long-term satisfaction with treatment choice in vestibular schwannoma. World Neurosurg. 2018;114: e1245-e1252.

47. Carlson ML, Vivas EX, McCracken DJ, et al. Congress of Neurological Surgeons systematic review and evidence-based guidelines on hearing preservation outcomes in patients with sporadic vestibular schwannomas. Neurosurgery. 2018;82(2): E35-E39.

48. Hadjipanayis CG, Carlson ML, Link MJ, et al. Congress of Neurological Surgeons systematic review and evidence-based guidelines on surgical resection for the treatment of patients with vestibular schwannomas. Neurosurgery. 2018;82(2): E40-E43.

49. Pollock BE. Management of vestibular schwannomas that enlarge after stereotactic radiosurgery: treatment recommendations based on a 15 year experience. Neurosurgery. 2006; 58(2):241-248.

50. Graffeo CS, Link MJ, Stafford SL, et al. More II it than meets the eye: outcomes after single-fraction stereotactic radiosurgery in a case series of low-grade arteriovenous malformations. Oper Neurosurg (Hagerstown). 2020;18(2): 136-144.

51. Chen L, Chen LH, Ling F, et al. Removal of vestibular schwannoma and facial nerve preservation using small suboccipital retrosigmoid craniotomy. Chin Med J (Engl). 2010; 123(3):274-280.

52. Perry A, Graffeo CS, Carlstrom LP, et al. Predominance of M1 subtype among tumor-associated macrophages in phenotypically aggressive sporadic vestibular schwannoma. J Neurosurg. Published online October 4, 2019. doi: 10.3171/2019.7.JNS19879

53. Zheng Z, Li J, Shen Y, et al. Radical intracapsular microenucleation technique for exclusively intraparotid facial nerve schwannoma: long-term follow-up review. J Craniomaxillofac Surg. 2016;44(12):1963-1969.

54. Bartindale M, Heiferman J, Joyce C, et al. The natural history of facial schwannomas: a meta-analysis of case series. $J$ Neurol Surg B Skull Base. 2019;80(5):458-468.

55. Hopewell JW, Millar WT, Lindquist C, et al. Application of the concept of biologically effective dose (BED) to patients with vestibular schwannomas treated by radiosurgery. $J R a$ diosurg SBRT. 2013;2(4):257-271.
56. Graffeo C, Donegan D, Erickson D, et al. The impact of insulin-like growth factor index and biological effective dose on outcomes after stereotactic radiosurgery for acromegaly. Neurosurgery. 2019;66(suppl 1):310-319.

57. Reitzen SD, Babb JS, Lalwani AK. Significance and reliability of the House-Brackmann grading system for regional facial nerve function. Otolaryngol Head Neck Surg. 2009; 140(2):154-158.

58. Banks CA, Jowett N, Hadlock TA. Test-retest reliability and agreement between in-person and video assessment of facial mimetic function using the eFACE facial grading system. JAMA Facial Plast Surg. 2017;19(3):206-211.

59. Fattah AY, Gurusinghe AD, Gavilan J, et al. Facial nerve grading instruments: systematic review of the literature and suggestion for uniformity. Plast Reconstr Surg. 2015;135(2): 569-579.

60. Carlson ML, Tveiten OV, Yost KJ, et al. The minimal clinically important difference in vestibular schwannoma qualityof-life assessment: an important step beyond $\mathrm{P}<.05$. Otolaryngol Head Neck Surg. 2015;153(2):202-208.

61. Carlson ML, Tombers NM, Kerezoudis P, et al. Quality of life within the first 6 months of vestibular schwannoma diagnosis with implications for patient counseling. Otol Neurotol. 2018;39(10):e1129-e1136.

62. Peris-Celda M, Graffeo C, Perry A, et al. Beyond the ABCs: hearing loss and quality-of-life in vestibular schwannoma. Mayo Clinic Proc. 2020. In press.

\section{Disclosures}

The authors report no conflict of interest concerning the materials or methods used in this study or the findings specified in this paper.

\section{Author Contributions}

Conception and design: Lu, Graffeo, Perry. Acquisition of data: Rotter, Lu. Analysis and interpretation of data: Link, Rotter, Lu. Drafting the article: Link, Rotter, Lu, Perry. Critically revising the article: Link, Lu, Graffeo, Perry, Pollock. Reviewed submitted version of manuscript: Rotter, Graffeo, Perry, Driscoll. Approved the final version of the manuscript on behalf of all authors: Link. Statistical analysis: Lu. Administrative/technical/material support: Lu, Graffeo, Perry. Study supervision: Link, Lu, Graffeo, Perry, Driscoll, Pollock.

\section{Supplemental Information \\ Online-Only Content}

Supplemental material is available with the online version of the article.

Supplemental Tables 1 and 2. https://thejns.org/doi/suppl/ 10.3171/2020.6.JNS201548.

\section{Correspondence}

Michael J. Link: Mayo Clinic, Rochester, MN. link.michael@ mayo.edu. 